Jurnal Health Sains: p-ISSN: 2723-4339 e-ISSN: 2548-1398

Vol. 2, No. 4, April 2021

\title{
TANTANGAN DALAM MENDUKUNG PROGRAM PENDIDIKAN GIZI SEKOLAH DI INDONESIA
}

\section{Mia Puspita Putri dan Ahmad Syafiq}

Universitas Indonesia, Depok, Jawa Barat, Indonesia

Email: miapuspitaputri10@yahoo.com dan asq69@yahoo.co.uk

\begin{tabular}{|c|c|}
\hline ARTIKEL INFO & ABSTRACT \\
\hline $\begin{array}{l}\text { Tanggal diterima: } 5 \text { April } 2021 \\
\text { Tanggal revisi: } 15 \text { April } 2021 \\
\text { Tanggal yang disetujui: } 25 \\
\text { April } 2021\end{array}$ & $\begin{array}{l}\text { Indonesia is one of the countries with a fairly high } \\
\text { prevalence of stunting compared to other low-income } \\
\text { countries. This study aims to evaluate the program of the } \\
\text { Nusantara movement in increasing the achievement of }\end{array}$ \\
\hline $\begin{array}{l}\text { Keywords: } \\
\text { knowledge; } \\
\text { education; school }\end{array}$ & $\begin{array}{l}\text { national education goals through a series of activities } \\
\text { aimed at improving (PSP) nutrition and health, eating a } \\
\text { nutritionally balanced diet, exercising and getting used to } \\
\text { drinking milk every day. The evaluation research in this } \\
\text { study uses secondary data from the Gernus activity report } \\
\text { with PKGK UI. The implementation of the Gernus program } \\
\text { from year to year has changed and improved. Some } \\
\text { programs that are implemented in the early years, } \\
\text { experience additions and improvements in the following } \\
\text { years, as needed. The results of the evaluation carried out } \\
\text { on nutrition education interventions in } 2014 \text { became a } \\
\text { reference for improving the implementation of the } \\
\text { intervention by seeing the magnitude of changes that } \\
\text { increased after 2014, namely from } 2015 \text { to } 2018 \text {. }\end{array}$ \\
\hline
\end{tabular}

\begin{abstract}
ABSTRAK
Indonesia menjadi salah satu negara dengan prevalensi stunting yang cukup tinggi dibandingkan negara-negara berpendapatan rendah lainnya. Penelitian ini bertujuan untuk mengevaluasi program gerakan nusantara dalam meningkatkan pencapaian tujuan pendidikan nasional melalui serangkaian kegiatan yang bertujuan untuk meningkatkan (PSP) gizi dan kesehatan, makan makanan yang bergizi seimbang, berolahraga dan membiasakan minum susu setiap hari. Riset evaluasi pada penelitian ini menggunakan data sekunder dari laporan kegiatan gernus bersama PKGK UI. Pelaksanaan program gernus dari tahun ke tahun mengalami perubahan dan perbaikan. Beberapa program yang dilaksanakan ditahun awal, mengalami tambahan dan perbaikan ditahun berikutnya, sesuai dengan kebutuhan. Hasil evaluasi yang dilakukan pada intervensi edukasi gizi di tahun 2014 menjadi acuan untuk perbaikan pelaksanaan intervensi dengan melihat besaran perubahan yang semakin meningkat setelah tahun 2014 yaitu mulai
\end{abstract}

Kata Kunci: pengetahuan; pendidikan gizi;

$\begin{array}{ll}\text { How to cite: } & \begin{array}{l}\text { Putri, Mia Puspita, et. al. (2021) Tantangan Dalam Mendukung Program Pendidikan Gizi Sekolah Di } \\ \text { Indonesia. Jurnal Health Sains 2(4). } \\ \text { http://jurnal.healthsains.co.id/index.php/jhs/article/view/142 }\end{array} \\ & \begin{array}{l}2723-6927 \\ \text { E-ISSN: }\end{array} \\ \text { Published by: } & \text { Ridwan Institute }\end{array}$



tahun 2015 sampai tahun 2018.

\section{Pendahuluan}

Menurut Pusat Data dan Informasi Kementrian Kesehatan RI tahun 2016, kondisi gizi pada anak usia sekolah masih membutuhkan perhatian, tercermin dari persentase stunting yaitu mencapai 30,7\%, artinya lebih dari satu per empat anak indonesia memiliki status gizi yang kurang. Saat ini indonesia menjadi salah satu negara dengan prevalensi stunting yang cukup tinggi dibandingkan negara-negara berpendapatan rendah lainnya (Kemendikbud, 2017). Oleh karena itu, diperlukan intervensi yang akan memberikan pendidikan gizi agar anak dapat menerapkan perilaku hidup sehat dan asupan gizi seimbang.

Banyaknya jajanan anak sekolah yang mengandung bahan kimia dan cemaran mikroba dapat menjadi peluang siswa untuk mengkonsumsi makanan yang tidak sehat. Salah satu upaya yang dapat dilakukan untuk menghindari anak sekolah dasar dari bahaya makanan jajanan yang tidak sehat adalah dengan memberikan edukasi gizi. Memberikan pendidikan tentang makanan sehat selama masa anak-anak tidak hanya dapat mencegah beberapa penyebab penyakit utama dan kematian, tetapi juga dapat menurunkan biaya kesehatan dan dapat meningkatkan kualitas hidup manusia (CDC, 2011)

Di Slovenia, pendidikan gizi merupakan bagian dari pembelajaran di semua tingkat sekolah dasar. Beberapa merupakan bentuk mata pelajaran yang wajib dan ada juga yang tidak (Kostanjevec et al., 2011). Menurut Penelitian (Drummond et al., 2012) juga menyebutkan edukasi gizi merupakan bagian terpenting dari kurikulum sekolah. Pendidikan gizi di lingkungan sekolah dapat memberikan pengaruh positif terhadap pengetahuan, sikap, dan tindakan anak-anak. Salah satu faktor penentu

Jurnal Health Sains, Vol 2, No 4, April 2021 keberhasilan program pendidikan gizi adalah metode yang digunakan (Kostanjevec et al., 2011).

Pembangunan dan pembinaan SDM yang berkualitas sangat baik dimulai sejak dini, yaitu saat usia sekolah. Anak usia sekolah mulai serius untuk mengeskpresikan ide menjadi lebih objektif dan mulai belajar menerima hal-hal baru dilihat dan didengar. Pembangunan dan pembinaan SDM yang berkualitas sangat baik dimulai sejak dini, yaitu saat usia sekolah. Anak usia sekolah mulai serius untuk mengeskpresikan ide menjadi lebih objektif dan mulai belajar menerima hal-hal baru dilihat dan didengar (Amrah, 2013).

Pedoman gizi seimbang disusun untuk menyempurnakan 4 sehat 5 sempurna. Hal ini dikarenakan slogan 4 sehat 5 sempurna tidak sesuai dengan kondisi dan permasalahan gizi saat ini (RI, 2014). Pedoman gizi seimbang perlu diperkenalkan kepada anak-anak. Salah satu cara yang dapat dilakukan ialah dengan pendidikan gizi.

Hasil penelitian (Februhartanty, 2005) membuktikan bahwa pendidikan gizi yang dilakukan pada anak usia sekolah efektif untuk mengubah pengetahuan dan sikap terhadap makanan. Anak usia sekolah lebih mudah untuk mengubah perilaku dibandingkan dengan orang dewasa. Pendidikan gizi yang diberikan diharapkan dapat meningkatkan pengetahuan anak usia sekolah dasar mengenai pedoman gizi seimbang. Pendidikan pedoman gizi seimbang pada anak sekolah dilakukan agar dapat mencetak generasi penerus bangsa yang berkualitas. Penting pula untuk menanamkan paradigma baru menggantikan paradigma 4 sehat 5 sempurna yang sudah tidak sesuai dengan permasalahan yang dihadapi saat ini.

Pendidikan gizi untuk anak sekolah diperlukan untuk mengatasi permasalahan 
tersebut. Anak sekolah menjadi sasaran kelompok masyarakat yang mudah dalam menerima dan menerapkan informasi baru. Pendidikan gizi untuk anak sekolah diberikan sejak dini akan memberikan dampak yang besar pada kesehatan anak di masa yang akan datang (Amrah, 2013).

Upaya perbaikan perilaku konsumsi anak yang tidak sehat ini dapat ditanggulangi dengan memberikan pengenalan serta pendidikan mengenai makanan sehat dan bergizi kepada anak sejak dini (Hikmayani, 2019). Anak-anak usia sekolah mulai diajarkan mengenai pentingnya makanan sehat dan bergizi. Upaya pendidikan ini tentunya lebih efektif jika diarahkan kepada Anak Usia Sekolah (AUS) dimana tingkat kerawanan gizi sering terjadi. Murid sekolah dasar masih belum dapat memilih makanan yang sehat dan bersih. Perilaku sadar gizi sejak usia dini perlu ditingkatkan melalui berbagai kegiatan penyuluhan dan pendidikan kesehatan.

Anak sekolah merupakan kelompok sasaran strategis untuk mencegah masalah gizi di masa depan. Melalui pendidikan gizi di sekolah dapat diharapkan tidak saja si anak mempunyai pengetahuan dan praktik dalam konsumsi makanan, akan tetapi mereka juga dapat mempengaruhi keluarganya untuk merubah kebiasaan yang salah (Emilia, 2009). Untuk itu diperlukan serangkaian upaya pemberdayaan murid sekolah dasar agar mereka mampu memelihara kesehatan dan gizi.

Program Gernus berupaya untuk meningkatkan pencapaian tujuan pendidikan nasional melalui serangkaian kegiatan yang bertujuan untuk menerapkan perilaku hidup sehat, makan makanan yang bergizi seimbang, berolahraga dan membiasakan minum susu setiap hari (Jalilah \& Prapitasari, 2021). Program Gernus digagas oleh PT. Frisian Flag Indonesia (FFI), dimulai sejak tahun 2013 dan menjangkau lebih dari 600.000 murid sekolah dasar yang tersebar di beberapa kota di Indonesia. FFI yang bekerjasama dengan Pusat Kajian Gizi dan Kesehatan Universitas Indonesia (PKGK UI) juga berupaya mengukur dampak perilaku sehat dan aktif anak melalui studi PSP (Pengetahuan-Sikap-Perilaku) pada tahun 2014 hingga 2018.

Penelitian ini bertujuan untuk mengevaluasi program gerakan nusantara dalam meningkatkan pencapaian tujuan pendidikan nasional melalui serangkaian kegiatan yang bertujuan untuk meningkatkan (PSP) gizi dan kesehatan, makan makanan yang bergizi seimbang, berolahraga dan membiasakan minum susu setiap hari.

\section{Metode Penelitian}

Penelitian ini dilakukan dengan analisis deskriptif dan analisis yang dilakukan secara kualitatif. Penelitian dilakukan dengan pendekatan riset evaluasi/ evaluation research terhadap pelaksanaan program gernus di sekolah dasar, dan analisis statistik yang dilakukan dengan menggunakan perangkat lunak Statistical Package for the Social Science (SPSS). Riset evaluasi pada penelitian ini menggunakan data sekunder yakni dari laporan kegiatan gernus bersama PKGK UI. Riset evaluasi terhadap pelaksanaan program dilakukan melalui pendekatan Context, Input, Process, Product (CIPP). CIPP merupakan model evaluasi yang mengarahkan objek sasaran evaluasinya pada proses dan masukan sampai hasil atau produk. Context berkaitan rencana program. Input berkaitan dengan sarana prasarana yang mendukung program. Process berkaitan dengan kegiatan program untuk mencapai tujuan, sedangkan produk berkaitan dengan hasil dari proses.

\section{Hasil dan Pembahasan}

Gerakan Nusantara dilatarbelakangi oleh hasil studi SEANUTS, yang menunjukkan bahwa anak-anak Indonesia mengalami double burden issue yaitu 
kekurangan gizi dan kelebihan berat badan. Selain itu anak-anak indonesia juga mengalami defisiensi Vitamin D, dengan tingkat keaktifan yang kurang. Ironis, karena Indonesia merupakan daerah banyak sinar matahari. Gerakan Nusantara dimulai oleh PT Frisian Flag Indonesia tahun 2013, dan sampai 2017 telah mencakup 2,507 Sekolah Dasar dengan 1,376,335 siswa. Gernus bertujuan untuk meningkatkan perilaku gaya hidup sehat aktif dan membiasakan minum susu setiap hari.

Kegiatan Gerakan Nusantara terdiri atas; kegiatan edukasi gizi bagi siswa di dalam kelas, kegiatan siswa di luar ruangan, pembagian susu untuk siswa, pembagian booklet edukasi gizi, renovasi dan sosialisasi kantin sehat, kegiatan pelatihan berupa Training of Trainers (TOT) tentang gizi bagi Guru, pelatihan Siswa, dan seminar orang tua. Kegiatan TOT guru pada tahun 2017 telah melatih langsung 2,254 guru dan menjangkau lebih dari 19,000 guru lainnya melalui kegiatan mandiri di sekolah masing-masing. Program Gerakan Nusantara juga mengukur dampak positif bagi perilaku sehat dan aktif anak melalui studi PSP (Pengetahuan-SikapPerilaku) yang dilakukan oleh PKGK UI, dimana pada 2015, 2016, dan 2017 secara umum menunjukkan hasil peningkatan yang signifikan dari pengetahuan gizi dan perilaku sehat aktif yang positif (Frisian Flag, 2017).

Program Gernus dimiliki dan digagas oleh PT Frisian Flag Indonesia (FFI). FFI bekerjasama dengan Pusat Kajian Gizi dan Kesehatan Universitas Indonesia (PKGK UI) dan Badan POM RI. Tujuan dari program gernus adalah untuk meningkatkan pencapaian tujuan pendidikan nasional melalui serangkaian kegiatan yang bertujuan untuk menerapkan perilaku hidup sehat, makan makanan yang bergizi seimbang, berolahraga dan membiasakan minum susu setiap hari.

Pelaksanaan program gernus dari tahun 2015 hingga 2018 mengalami perbedaan.
Terlihat dari mekanisme yang tertera pada tahun 2015 yang mencakup pelatihan guru, edukasi gizi siswa (aktivasi) yang mencakup aktivitas fisik anak diluar ruangan dan pembagian susu untuk siswa, pelatihan siswa, diari guru dan survey PSP. Di tahun 2016 ada tambahan edukasi gizi guru oleh Tim PKGK UI, seminar orang tua yang juga diberikan oleh pemateri dari Tim PKGK UI dan pelatihan siswa yang bertujuan untuk melatih siswa jadi tutor sebaya (peer) yang akan memberikan edukasi pada teman-teman sesama siswa.

Pelatihan ini juga diberikan oleh Tim PKGK UI. Namun ditahun 2017 dan 2018 pelatihan untuk siswa sudah ditiadakan, target program hanya diberikan untuk guru, siswa dan orang tua. Di tahun 2017, seminar orang tua diserahkan kepada pihak sekolah untuk dikelola dan dilaksanakan sendiri.

Pada tahun 2017 dan 2018 program Training of Trainers (TOT) bertujuan untuk memberikan pelatihan pada guru perwakilan dari sekolah yang ditunjuk, yang kemudian diharapkan guru yang sudah diberikan pelatihan ini memberikan edukasi pada sesama guru kelas di sekolah dan guru-guru dari sekolah terdekat sebanyak tiga kali selama dua minggu. Program TOT pada tahun 2017 dipantau oleh tim peneliti di bulan terakhir yaitu bulan ketiga. Namun pada tahun 2018, program TOT diserahkan kepada pihak sekolah untuk dilaksanakan secara mandiri.

Di akhir rangkaian program gerakan nusantara ini dilakukan post-test untuk mengetahui apakah ada perubahan terhadap pengetahuan, sikap dan perilaku guru, siswa dan orang tua setelah diberikan intervensi pelatihan dan edukasi gizi sekolah melalui program gerakan nusantara ini (Lingga, 2015). Untuk menilai keberhasilan dari program gernus, dilakukan evaluasi terhadap pelaksanaan program. Evaluasi terhadap pelaksanaan program dilakukan melalui 
pendekatan Context, Input, Process, Product (CIPP).

Program gernus diarahkan pada efisiensi dan kemandirian program gizi di sekolah dasar dengan memberikan pelatihan gizi kepada siswa, orang tua, kepala sekolah dan guru. Program gernus bertujuan untuk meningkatkan pengetahuan, sikap dan perilaku gizi dan kesehatan siswa SD. Dari segi kebutuhan yang akan dicapai terdiri dari materi gizi dan kesehatan yang akan didapatkan siswa.

Input, terdiri dari persiapan program, fasilitas pendukung dan sumber daya manusia. Persiapan yang dilakukan meliputi dimana kegiatan akan dilakukan, kegiatan apa yang akan dilaksanakan, fasilitas yang akan digunakan, serta perserta yang terlibat didalam program.

Process meliputi jenis kegiatan yang terdiri dari pelatihan guru, edukasi siswa, edukasi pada guru disekolah, pelatihan siswa, survey Pengetahuan, Sikap dan Perilaku (PSP), diari guru dan catatan siswa, Aktivasi berupa aktivitas fisik diluar ruangan, pemberian susu dan edukasi gizi, seminar orang tua dan program Training of Trainers (TOT) bagi guru. Selanjutnya pada bagian process juga ditemukan kendala pelaksanaan kegiatan secara teknis dan keterlibatan siswa, guru dan orang tua.

Product yang merupakan hasil yang diharapkan dari program gernus adalah program gernus terbukti meningkatkan pengetahuan gizi siswa, meningkatkan sikap siswa mengenai gizi seimbang, serta meningkatkan nilai perilaku gizi siswa disekolah. Peningkatan pengetahuan, sikap dan perilaku ini berhubungan dengan edukasi yang diberikan tidak hanya kepada siswa sendiri, namun kepada teman sebaya, guru disekolah dan orang tua dirumah. Pemberian edukasi gizi pada siswa termasuk kepada lingkungan sosial siswa terbukti dapat meningkatkan pengetahuan, sikap dan perilaku gizi siswa. Hal ini sejalan dengan penelitian yang dilakukan oleh (Tsang \& Jiang, 2018) bahwa perilaku anak dipengaruhi oleh teman sebaya, guru, orang dewasa, dan orang tua.

Anak akan lebih mudah meniru perilaku makan teman sebaya mereka karena menganggap perilaku makan tersebut merupakan hal yang umum diterima dan disukai oleh kelompok usia mereka, sedangkan orang dewasa dapat memberikan pengaruh yang lebih kuat kepada anak-anak, dan orang tua memainkan peranan penting dalam membentuk pola makan anak di awal kehidupan, karena orang tua dirumah sebagai penyedia dan pengendali makanan apa saja yang akan dimakan, serta menjadi teladan, membentuk sikap dan perilaku anak terhadap makanan. Selain itu, kemitraan orang tua dengan sekolah juga dapat mempengaruhi pengetahuan, sikap dan keterampilan anak (Diananda, 2019).

Program gernus selain untuk meningkatkan promosi kesehatan melalui sekolah, kegiatan ini juga melibatkan promosi kesehatan kepada orang tua siswa melalui kegiatan seminar orang tua. Hal ini sejalan dengan penelitian yang dilakukan (Zulaikha, 2009) mengenai pendidikan gizi secara komprehensif untuk mengatasi anemia, berkesimpulan bahwa pendidikan gizi secara komprehensif dengan melibatkan anak, orang tua/wali dan guru kelas dipadukan dengan pemberian asupan langsung kepada anak lebih efektif dan memberikan dampak positif dibandingkan jika hanya diberikan pendidikan saja.

\section{Kesimpulan}

Keberhasilan program gerakan nusantara dicapai karena program kegiatan melibatkan semua kalangan yang berhubungan dengan lingkungan sosial siswa yakni guru disekolah, teman sebaya dan orang tua, kegiatan dilakukan secara nyata melalui pelatihan siswa, praktik dan pemberian makanan sehat. Gerakan nusantara secara 
konsisten terus berupaya mempertahankan pencapaian tujuan pendidikan nasional melalui serangkaian kegiatan yang bertujuan untuk meningkatkan pengetahuan, sikap dan perilaku (PSP) gizi dan kesehatan, makan makanan yang bergizi seimbang, berolahraga dan membiasakan minum susu setiap hari.

Keberlanjutan program gerakan nusantara sangat penting dipertahankan agar dapat dijadikan teladan bagi program edukasi gizi nasional.

\section{BIBLIOGRAFI}

(Cdc), C. For D. C. And P. (2011). Vital Signs: Prevalence, Treatment, And Control Of High Levels Of Low-Density Lipoprotein Cholesterol-United States, 1999-2002 And 2005-2008. Mmwr

Morb Mortal Wkly Rep, 60(4), 109-114. Google Scholar

Amrah, A. (2013). Perkembangan Moral Anak Usia Sekolah Dasar. Publikasi Pendidikan, 3(1). Google Scholar

Diananda, A. (2019). Psikologi Remaja Dan Permasalahannya. Istighna: Jurnal Pendidikan Dan Pemikiran Islam, 1(1), 116-133. Google Scholar

Drummond, A. J., Suchard, M. A., Xie, D., \& Rambaut, A. (2012). Bayesian Phylogenetics With Beauti And The Beast 1.7. Molecular Biology And Evolution, 29(8), 1969-1973. Google Scholar

Emilia, E. (2009). Pengetahuan, Sikap Dan Praktek Gizi Pada Remaja Dan Implikasinya Pada Sosialisasi Perilaku Hidup Sehat. Media Pendidikan, Gizi, Dan Kuliner, 1(1). Google Scholar

Februhartanty, J. (2005). Nutrition Education: It Has Never Been An Easy Case For Indonesia. Food And Nutrition Bulletin, 26(2_Supp12), S267-S274. Google Scholar

Hikmayani, A. S. (2019). Fuge Fun Upaya
Pengenalan Makanan Bergizi Dan Peningkatan Kreativitas Anak Usia Dini. Jurnal Pelita Paud, 3(2), 82-94. Google Scholar

Jalilah, N. H., \& Prapitasari, R. (2021). Kesehatan Reproduksi Dan Keluarga Berencana. Penerbit Adab. Google Scholar

Kemendikbud, T. (2017). Konsep Dan Pedoman Penguatan Pendidikan Karakter Tingkat Sekolah Dasar Dan Sekolah Menengah Pertama. Jakarta: Kemdikbud. Google Scholar

Kostanjevec, S., Jerman, J., \& Koch, V. (2011). The Effects Of Nutrition Education On 6th Graders Knowledge Of Nutrition In Nine-Year Primary Schools In Slovenia. Eurasia Journal of Mathematics, Science And Technology Education, 7(4), 243-252. Google Scholar

Lingga, N. L. (2015). Pengaruh Pemberian Media Animasi Terhadap Perubahan Pengetahuan Dan Sikap Gizi Seimbang Pada Siswa Kelas Vi Sekolah Dasar Negeri Tanjung Duren Utara 01 Pagi Jakarta Barat. Program Studi Ilmu Gizi Fakultas Ilmu Kesehatan Universitas Esa Unggul Jakarta. Google Scholar

Ri, K. (2014). Pedoman Pelaksanaan Stimulasi, Deteksi Dan Intervensi Dini Tumbuh Kembang Anak Ditingkat Pelayanan Kesehatan Dasar. Jakarta2012. Google Scholar

Tsang, K. K., \& Jiang, L. (2018). Sociological Understandings Of Teachers' Emotions In Second Language Classrooms In The Context Of Education/Curricular Reforms: Directions For Future Research. In Emotions In Second Language Teaching (Pp. 73-89). Springer. Google Scholar

Zulaikha, S. (2009). Peningkatan Hasil Belajar Siswa Dalam Mata Diklat Akuntansi Dengan Menggunakan Pendekatan Pembelajaran Berbasis 
Mia Puspita Putri dan Ahmad Syafiq

Masalah (Problem Based Learning) Di

Smk Pgri 6 Malang. Universitas Negeri

Malang. Google Scholar

\section{Copyright holder :}

Mia Puspita Sari dan Ahmad Syafiq (2021)

First publication right :

Jurnal Health Sains

This article is licensed under:

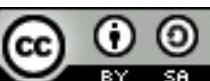

